UTC 577.1

\title{
RADIOPROTECTIVE EFFECT OF RAMSON (ÁLLIUM URSÍNUM L.) AND BOG BILBERRY (VACCINIUM ULIGINOSUM L.)
}

\author{
(C) V.E. Tarabanko ${ }^{I^{*}}$, E.T. Rodionov ${ }^{2}$, L.B. Toporkova ${ }^{3}$, S. Muench ${ }^{4}$, I.A. Orlovskaya ${ }^{3}$ \\ ${ }^{1}$ Institute of Chemistry and Chemical Technology SB RAS, Akademgorodok, 50/24, \\ Krasnoyarsk,660036 (Russia), e-mail veta@icct.ru \\ ${ }^{2}$ LTD «Dikorosy», Zatonskaya St., 29A, bl. 12, Krasnoyarsk, 660052, (Russia) \\ ${ }^{3}$ Scientific Research Institute of Clinical immunology, Siberian Branch, Russian \\ Academy of Medical Sciences, Yadrintsevskaya, 14, Novosibirsk, 630099 (Russia) \\ ${ }^{4}$ IOANESSI GmbH, Innovationspark, Marie-Curie-Str. 8, 51377 Leverkusen, \\ (Germany)
}

Radioprotective properties of the products produced from ramson (Állium Ursinum L.) and bog bilberry (Vaccinium uliginosum L.) were studied. Mice fed with the dried ramson and the bog bilberry extract were irradiated by X-rays (8 Gray). Strong radioprotective effect of these plant products was registered. The ramson demonstrated more radioprotective effect in comparison with bog bilberry extract. The radioprotective effect of Allium is probably determined by cysteine sulfoxides and their degradation products, such as diallyl disulfide and allyl methyl disulfide. The radioprotectors studied increase minimum parameters of erythropoiesis (red blood cell number and hematocrit) by a factor 1,5. Rapid recovery of the parameter of the platelets number of peripheral blood in all groups in comparison with control was registered. The survival of mice fed with the dried ramson and the bog bilberry extract increased up to 60 and 53\%, correspondingly, in comparison with 6,7\% in the control group. These substances do not have side effects and contraindications and may be considered as a promising radioprotectors.

Keywords: Radioprotector, ramson, Állium Ursínum, bog bilberry, Vaccinium uliginosum, mice, X-ray.

\section{Introduction}

A major accident at the nuclear power plant in Fukushima demonstrated once again the real danger of radiation damage to the nature, staff and people in the disaster area. The radiation therapy of cancer is associated with high doses of irradiation. The astronauts are irradiated by high doses of radiation as well as the air transport passengers to a lesser extent. To minimize the negative effects of such impacts the effective and nontoxic radioprotectors, which can be taken regularly in a preventive mode are required. Synthetic derivatives of biogenic amines, such as mexamine, indralin are radioprotectors of emergency effect [1]. Negative side effects of these drugs preclude their systematic use as a prophylactic measure.

Special natural polysaccharides increase the survival of animals to 60-80 at 100\% mortality in controls, but the radioprotective effect is lost when taken orally [2].

The adaptogens such as ginseng root water-soluble extracts appear to give a protection against radiationinduced DNA damage [3]. On the other hand, ginseng, wolfberry, Manchurian Aralia do not protect the rats irradiated at a dose of $7 \mathrm{~Gy}$ [2]. Vitamin $\mathrm{E}$ is suitable to prevent possible damage by ionizing radiation [4]. Pelargonidin-3,5-diglucoside anthocyanin has been found to protect mice irradiated with doses of 3-9 Gy (the fac-

Tarabanko Valery E. - the head of laboratory for biomass conversion, professor, e-mail: veta@icct.ru

Rodionov Evgeniy T. - General Director of «Dal-Ekspress» Association

Toporkova Ludmila B. - Senior researcher of laboratory for immunobiology of stem cell, Ph.D.

Muench Sergey - Director of IOANESSI GmbH

Orlovskaya Irina A. - the head of laboratory for immunobiology of stem cell, Ph.D. tor of dose increasing is 1,7) [5].

Ramson was patented as a component for the space canned food with high digestibility [6], and was used by the Soviet cosmonauts [7], but radioprotective properties of Állium Ursinum have not been studied.

The main goal of this research is to demonstrate the radioprotective properties of ramson (Állium

\footnotetext{
* Corresponding author.
} 
Ursinum L.). In addition to the control group to compare the effect of radioprotection we included the group of mice fed the bog bilberry (Vaccinium uliginosum L.) extract. The bog bilberry extract contains high concentrations of anthocyanins with antioxidant and radioprotective properties [5].

\section{Materials and methods}

The study was carried out with male mice (CBAxC57Bl / 6) F1-hybrids. The mice were divided into seven groups, and each group contained 15 animals in one big cage. The mice were fed ramson (group AU1-AU3) and bog bilberry extract (group VU4-VU6) daily for 2 weeks before exposure and for a week after irradiation.

Dry powder of ramson and extract (concentrated juice) of bog bilberries were used in the experiments. Dry substance content in the bog bilberry extract was $24,1 \mathrm{wt} . \%$. The concentration of anthocyanins in terms of malvidin-3-glucoside was determined by spectrophotometry [8] and equaled to $81,7 \mathrm{mg} / \mathrm{ml}$. These products were mixed in porridge (a standard component of the diet) in the following amounts per day for 15 animals in groups: AU1 - 150 mg, AU2 - 300 mg, AU3 - 900 mg, VU4 - 2 ml, VU5 - $5 \mathrm{ml}$, VU6 - 10 ml.

Doses of protectors were calculated on the basis of known doses used for humans, and taking into account the increased metabolism of mice in comparison with a man. The control mice were fed porridge without any additives.

All animals were irradiated with the dose of $8 \mathrm{~Gy}$ in the Roentgen instrument RUM-25 (Russia) at the dose capacity of $0,5 \mathrm{~Gy} / \mathrm{min}$, voltage of $130 \mathrm{kV}$, and electric current of $10 \mathrm{~mA}$. The dose of $8 \mathrm{~Gy}$ was selected, because it allows studying the survival potential of animals, an integral indicator of the radiation protection.

All mice were weighed before the irradiation. After irradiation the parameters of peripheral blood were studied in the dynamics of hematopoiesis recovery (30 days) with the PCE-90 (ERMA Inc., Japan) analyzer. The dynamics of the mice death was determined within 30 days after irradiation.

Results are reported as the average mean \pm standard deviation of individual data points obtained from experiments.

\section{Results}

Weighting the mice prior to irradiation showed that feeding with maximum quantity of the substances (AU3 and VU6) for 2 weeks leads to a significant decrease in mass index of mice (Table). This decrease is a reliable value, because the standard deviation of the average mass value is of four times less as compared to the standard deviation of measurement due to its high statistics (15 experiments). These results may mean that the maximum doses of ramson and the bog bilberry extract, used in this test, worsen the state of the mice prior to irradiation and can not be exceeded without some negative consequences.

The survival of experimental animals during the 30-day period after irradiation is shown in Fig. 1. These results clearly show that the ramson and bog bilberry products feeding significantly increase survival of the animals. The survival of control mice was $6,7 \%$, the dried ramson increases the survival to $20-60 \%$, and the bog bilberry extract does to $47-53 \%$. The best survival is observed in the mice group fed high doses of ramson. For the bog bilberry extract the radioprotective activity may be determined by high concentrations of anthocyanins and their antioxidant activity [5]. The ramson radioprotective properties are not previously described except [9] and slightly surpasses the efficiency of the bog bilberry extract. There is unclear, what ramson chemicals are responsible for the radioprotective effect, but antibiotic, antioxidative, antidiabetic, and cancer-preventing properties of Allium are probably determined by cysteine sulfoxides and their degradation products, such as diallyl disulfide and allyl methyl disulfide [10]. The radioprotective effect observed may be associated with these specific compounds of Allium Ursinum L.

The parameters of peripheral blood before and after irradiation are shown in the figures 2-5. Ramson significantly increase the number of white blood cells in comparison with controls prior to irradiation. The dynamic study of the parameters of peripheral blood revealed that the radioprotectors 1) have no negative effect on the hemopoiesis recovery, 2) in some cases accelerate this process. All the minimum parameters of peripheral blood are attained in the 6th -16 th days. All the radioprotectors increase minimum parameters of erythropoiesis (red blood cell number and hematocrit) by a factor 1,5 in 13 th day as compared to the control values. On the 26th day ramson increase the number of white blood cells in comparison with controls.

Mass (grams) averages (and its standard deviation) of the experimental mice fed ramson and bog bilberry extract for 2 weeks

\begin{tabular}{c|c|c|c|c|c|c}
\hline Control & AU1 & AU2 & AU3 & VU4 & VU5 & VU6 \\
\hline $30,7 \pm 2,8$ & $30,7 \pm 2,7$ & $30 \pm 3,2$ & $27,9 \pm 1,7$ & $29 \pm 1,8$ & $29,6 \pm 1,9$ & $27,9 \pm 2,8$ \\
\hline
\end{tabular}




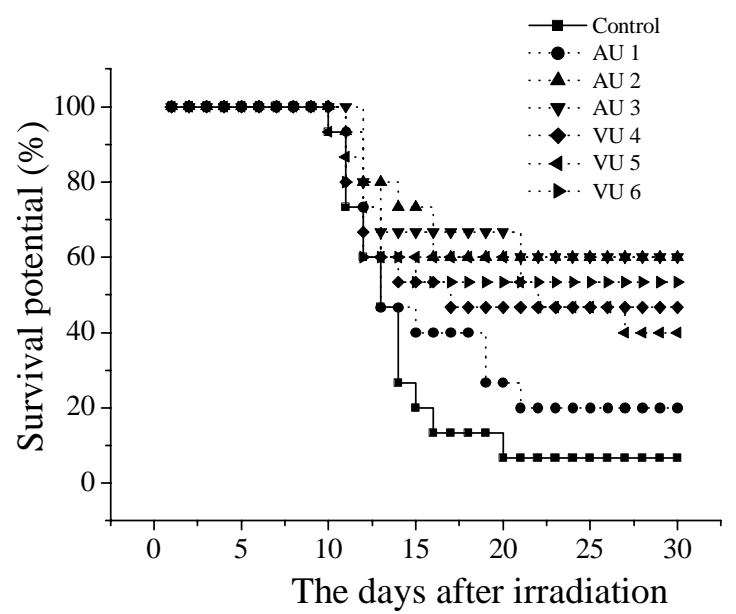

Fig. 1. The effect of ramson and bog bilberry extract on the survival of the mice after the irradiation

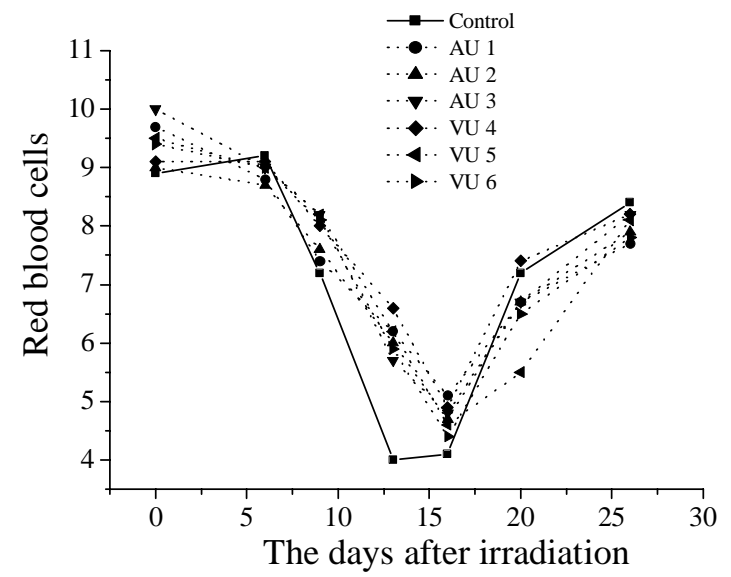

Fig. 3. The effect of the dried ramson and the bog bilberry extract on the dynamics of red blood cells number $(109 / \mathrm{ml})$ after the irradiation of the mice

Fig. 5. The effect of the dried ramson and the bog bilberry extract on the dynamics of the platelets number $(106 / \mathrm{ml})$ after the irradiation of the mice

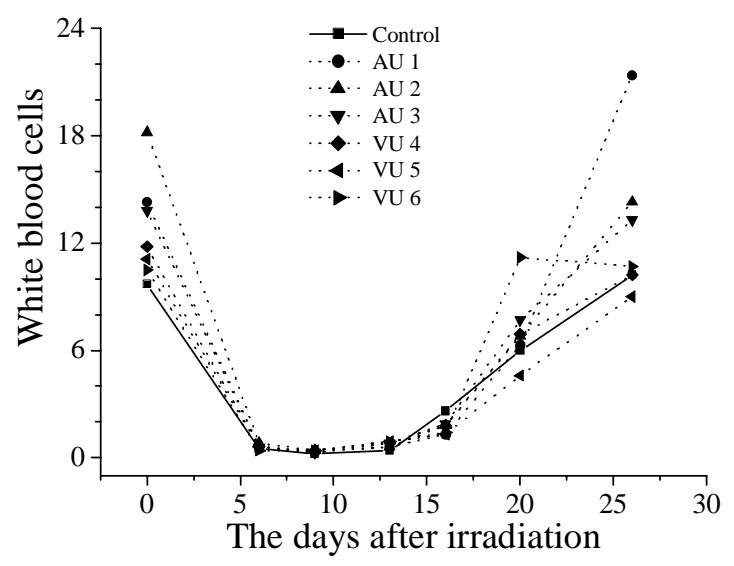

Fig. 2. The effect of the dried ramson and the bog bilberry extract on the dynamics of the white blood cells number $(106 / \mathrm{ml})$ after the irradiation of the mice

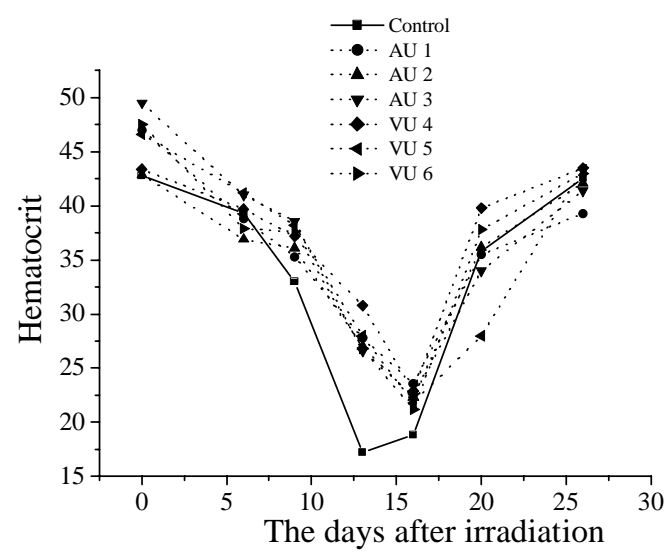

Fig. 4. The effect of the dried ramson and the bog bilberry extract on the dynamics of hematocrit $(\%)$ after the irradiation of the mice

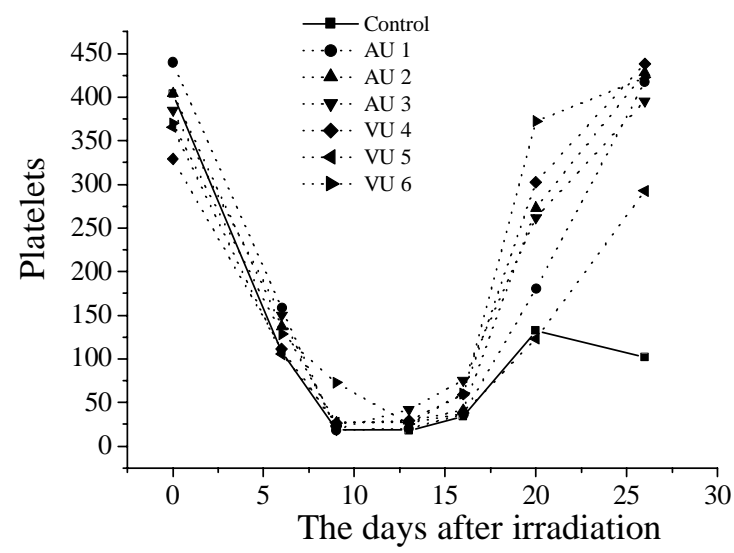

The most notable is the parameter of the platelets number. The rapid recovery of platelets is important to prevent hemorrhage, attending the clinical course of radiation sickness. In our studies, starting from the 16th day, there is the rapid recovery of this parameter in all groups in comparison with control.

\section{Conclusion}

The experiments made with mice show the major radioprotective potential of the concentrated products of ramson (Állium Ursínum L.) and bog bilberries (Vaccinium uliginosum L.). The results obtained indicate that the 
dried ramson and the bog bilberry extract protect mice against radiation-induced lethality. The survival of the control mice group is $6,7 \%$; the dried ramson increases the survival rate up to $20-60 \%$; and bog bilberry extract - to $47-53 \%$, depending on the amount of the radioprotectors. The protectors used increase the restoration rate of red blood cells and platelets numbers in the blood in comparison with the control, and improve the minimum blood parameters after irradiation, such as red blood cell number and hematocrit.

The radioprotective effect of bog bilberry extract is rather predictable and can be associated with the antioxidant properties of anthocyanins contained in it. In contrast, the radioprotective properties of ramson have not been previously described and patented recently [9].

It should be noted that the dried ramson is more effective in comparison with the bog bilberry extract under the studied conditions. It has no side effects and contraindications and may be considered as a promising radioprotector.

\section{References}

1. Vasin M.V. Antiradiation medicines, Moscow, 2010. 182 p. (in Russ.)

2. Goncharenko E.N., Kudryashov E.B. Advances in modern biology, 1991, vol. 111, no. 2, pp. 302-316. (in Russ.)

3. Lee T.K., Johnke R.M., Allison R.R., O'Brien K.F., Dobbs L.J. Jr. Mutagenesis, 2005, vol. 20, no. 4, pp. $237-243$.

4. Paranich A.V., Konsesao A., Bugay E.V., Kopylov A.V. Radiobiology, 1992, vol. 32, no. 5, pp. 743-749. (in Russ.).

5. Akhmadieva A.H., Zaichkina S.I., Ruzieva A.D., Ganassi E.E. Radiobiology, 1993, vol. 33, no. 3, pp. 433-435. (in Russ.)

6. $\quad$ Patent 2338402 (RU). 2008. (in Russ.)

7. Dobryuha N. Yurii Gagarin. Seldom photos. Izvestiya. (Russia). 2006. April 12. (in Russ.).

8. Valuiko G.G. Biochemistry and technology of red wines. Food Industry, Moscow, 1973. 256 p.

9. Patent 2458700 (RU). 2012. (in Russ.).

10. Schmitt B., Schulz H., Storsberg J., Keusgen M. J. Agric. Food Chem., 2005, vol. 53, pp. 7288-7294.

Received February 27, 2015 